\title{
Teleconsulta médica: os limites éticos e o risco de negligência informacional
}

Medical teleconsultation: ethical limits and the risk of informational negligence

Teleconsulta médica: límites éticos y riesgo de negligencia informativa

Vinicius de Negreiros Calado ${ }^{1}$

Marcelo Lamy²

\section{Resumo}

Objetivo: levantar a legislação vigente sobre a teleconsulta e realizar sua análise a partir do conceito de consulta médica e da necessidade do exame físico direto do paciente para a sua caracterização, bem como as limitações impostas pelo Código de Ética Médica (CEM) do Conselho Federal de Medicina (CFM), por seus pareceres e resoluções dos Conselhos Regionais, visando apontar seus limites e riscos de negligência médica informacional. Metodologia: revisão qualitativa e integrativa da legislação vigente, da literatura médica e jurídica especializada. Resultados: a prática da telemedicina é regulada pelo Conselho Federal de Medicina (CFM), mas a teleconsulta não é expressamente reconhecida pela entidade. Após a vigência da Portaria do Ministério da Saúde (MS) no 467/2020 e da Lei no 13.989/2020, que expressamente permitem a teleconsulta em caráter excepcional e transitório, evidenciou-se que os Conselhos Regionais de Medicina dos estados adotaram posicionamentos divergentes quanto ao tema. Demonstrou-se ainda que o parecer do Conselho Federal de Medicina nำ14/2017 é vinculante e possibilita a comunicação entre o médico e o seu paciente por recursos tecnológicos, quando já houver entre eles uma relação anterior. Conclusão: a teleconsulta é prática médica ética e possível, posto que não é proibida pela Resolução CFM no 1.643/2002, abordada diretamente no Parecer CFM no 14/2017, mas que depende de prévia relação médico-paciente para as situações ordinárias, estando diferida (e nunca dispensada) em situações de emergenciais e sendo necessária a formalização de termo de consentimento informado digital por qualquer meio de tecnologia da informação e comunicação, desde que garanta a integridade, segurança e o sigilo das informações.

Palavras-chave: Consulta remota. Códigos de ética. Imperícia.

\footnotetext{
Abstract

Objective: to analyze the current legislation on teleconsultation, based on the concept of medical consultation and the need for the physical examination of the patient for its characterization, as well as the limitations imposed by the Code of Medical Ethics of the Federal Council of Medicine (FCM), and by the opinions and resolutions of the Regional Councils, aiming to point out its limits and risks of informational medical negligence.

1 Doutor em Direito, Universidade Católica de Pernambuco (Unicap), Recife, Pernambuco, Brasil; professor, Faculdade de Direito, Universidade Católica de Pernambuco (Unicap), Recife, Pernambuco, Brasil. https://orcid.org/0000-0002-71516261. E-mail: vinicius.calado@unicap.br

2 Doutor em Direito Constitucional, Pontifícia Universidade Católica (PUC), São Paulo, SP, Brasil; professor permanente e vice-coordenador, Programa de Pós-Graduação em Direito da Saúde, Universidade Santa Cecília (Unisanta), Santos, São Paulo, Brasil. http://orcid.org/0000-0001-8519-2280. E-mail: marcelolamy@unisanta.br
} 
Methods: qualitative and integrative review of current legislation, specialized medical and legal literature on the issue. Results: The practice of telemedicine is regulated by the Federal Council of Medicine, but teleconsultation is not expressly recognized by the entity. After the entry into force of the Administrative Rule No. 467/2020 from Ministry of Health and Law No. 13,989/2020, which expressly allows for teleconsultation in an exceptional and transitory nature, it was found that the Regional Councils of Medicine of the states adopted divergent positions regarding the theme. It was also evident that the opinion of the Federal Council of Medicine No. 14/2017 is binding and allows a "communication" between the doctor and his patient by technological resources, as long as these are already served by him. Conclusion: teleconsultation is an ethical and possible medical practice, since it is not prohibited by CFM Resolution No. 1,643/2002, addressed directly in Report FCM no 14/2017, but it depends on a previous doctor-patient relationship for ordinary situations, being deferred (and never dispensed) in emergency situations, being the formalization of digital informed consent by any means of information and communication technology is necessary, as long as it guarantees the integrity, security and confidentiality of information.

Keywords: Remote consultation. Codes of ethics. Malpractice.

\section{Resumen}

Objetivo: analizar la legislación vigente sobre la teleconsulta, basada en el concepto de consulta médica y la necesidad del examen físico cara a cara del paciente para su caracterización, así como las limitaciones impuestas por el Código de Ética Médica (CEM) del Consejo Federal de Medicina (CFM), por sus opiniones y resoluciones de los Consejos Regionales, con el objetivo de señalar sus límites y riesgos de negligencia médica informativa. Metodología: revisión cualitativa e integradora de la legislación vigente, la literatura médica y legal especializada sobre el tema. Resultados: El ejercicio de la telemedicina está regulado por el Consejo Federal de Medicina, pero la teleconsulta no está reconocida expresamente por la entidad. Luego de la entrada en vigor de la ordenanza del Ministerio de Salud (MS) No. 467/2020 y la Ley No. 13.989/2020, que permiten expresamente la teleconsulta con carácter excepcional y transitorio, se evidenció que los Consejos Regionales de Medicina de los estados adoptaron posiciones divergentes respecto al tema. También se evidenció que la opinión del Consejo Federal de Medicina nำ14/2017 es vinculante y permite la "comunicación" entre el médico y su paciente por los recursos tecnológicos, siempre que estos ya sean atendidos por él. Conclusión: la teleconsulta es una práctica médica ética y posible, ya que no está prohibida por la Resolución CFM N ${ }^{\circ}$ 1.643 / 2002, abordado directamente en la opinión del CFM no 14/2017, pero depende de una relación previa médico-paciente para situaciones ordinarias, diferirse (y nunca dispensarse) en situaciones de emergencia. La formalización de las TIC digitales por cualquier medio de tecnología de información y comunicación es necesaria, siempre que garantice la integridad, seguridad y confidencialidad de la información.

Palabras clave: Consulta remota. Códigos de ética. Mala praxis.

\section{Introdução}

O Brasil relutou em regulamentar o exercício da telemedicina de modo amplo e definitivo, ocasionando muitas dúvidas e insegurança quanto a sua prática, levando aqueles que se dispuseram a desenvolver tal atividade, notadamente na área privada, a solicitar ao Conselho Federal de Medicina (CFM) que se manifestasse especificamente sobre o tema, o 
que ocorreu por meio de pareceres-consultas, os quais, por sua vez, foram consolidando o entendimento sobre o tema ao longo do tempo.

Contudo, o mundo inteiro foi surpreendido pela pandemia do coronavírus, reconhecida pela Organização Mundial da Saúde (OMS), e em face desse momento extraordinário vivenciado, soluções urgentes precisaram ser adotadas.

Nesse sentido, é de se reconhecer que o ponto de partida efetivo para o enfretamento do problema foi o Projeto de Lei (PL) n 696, 18 de março de 2020, de autoria da deputada Adriana Ventura (Novo/SP), visando dispor sobre o uso da telemedicina durante a crise causada pelo coronavírus. Na justificativa do projeto de Lei está grafado: "[...] deve ser dispensável qualquer requisito burocrático para o exercício da telemedicina. O mais importante é assegurar à nossa população a continuidade do atendimento" (1).

No dia seguinte, o CFM encaminhou o Ofício CFM № 1.756/2020 - COJUR (2) ao Ministro da Saúde da época, Luiz Henrique Mandetta, reconhecendo "a possibilidade e a eticidade da utilização da telemedicina, além do disposto na Resolução CFM nำ1.643, de 26 de agosto de 2002" apenas para teleorientação, telemonitoramento e teleinterconsulta (3). O Ministério da Saúde (MS), então, editou a Portaria MS nำ467, de 20 de março de 2020 (4), regulando a matéria, indo além da visão restritiva contida no escopo do ofício do Conselho Federal de Medicina (CFM), pois acolheu o atendimento pré-clínico, de suporte assistencial, de consulta, monitoramento e diagnóstico. Mesmo após a publicação da Portaria do Ministério da Saúde e do Projeto de Lei, o CFM não editou ou modificou suas resoluções que tratam da telemedicina, o que levou os Conselhos Regionais de Medicina estaduais a editarem resoluções sobre o tema, gerando ainda mais insegurança.

Menos de um mês após a sua apresentação, o Projeto de Lei (PL) no 696, de 18 de março de 2020 (1) foi aprovado, com algumas modificações, e entrou em vigor a Lei no 13.989, de 15 de abril de 2020 (5), que dispõe sobre o uso da telemedicina durante a crise causada pelo coronavírus (SARS-CoV-2), autorizando o seu uso, de modo muito amplo, pois abre-se para todas as formas de assistência, pesquisa, prevenção de doenças e lesões e promoção de saúde, embora constitua autorização excepcional e emergencial, enquanto durar a mencionada crise.

Assim, há lei válida e vigente tratando da telemedicina no Brasil, o que justifica a necessidade de aprofundamento do tema, em especial pelo reconhecimento da possibilidade da teleconsulta e de suas peculiaridades. 


\section{Metodologia}

A pesquisa realizou o levantamento da legislação vigente sobre a telemedicina a partir de pareceres e resoluções do CFM, bem como das resoluções dos Conselhos Regionais de Medicina sobre o tema. A base de dados consultada restringiu-se aos sítios eletrônicos dos Conselhos de Medicina e do Diário Oficial da União, tendo em vista serem as fontes oficiais de publicação das normas em questão. O critério norteador para a busca foi a filtragem lexical pela palavra telemedicina.

Após o levantamento quantitativo, realizou-se um segundo filtro, a partir da apreciação de cada documento original encontrado para verificar sua pertinência com o tema específico da teleconsulta (Quadro 1). A pesquisa foi realizada no período de 10 a 18 de junho de 2020 e evidenciou a existência de duas normas vigentes (e uma revogada), emanadas do CFM e que disciplinam e norteiam o tema, inclusive sem relação com a pandemia decorrente do coronavírus (Covid-19). Foram evidenciadas seis normas emanadas dos Conselhos Regionais de Medicina que versam sobre o tema, mas que foram baixadas durante a pandemia, ocorrendo o mesmo com as duas normas federais. O estudo também analisa a norma do CFM que trata sobre a consulta médica, da qual a teleconsulta seria uma espécie.

Quadro 1. Normas consultadas

\begin{tabular}{|l|l|l|}
\hline $\begin{array}{c}\text { Autoridade normativa } \\
\text { (Fonte) }\end{array}$ & \multicolumn{1}{|c|}{ Norma } & \multicolumn{1}{c|}{ Síntese da norma } \\
\hline $\begin{array}{l}\text { Conselho Federal de } \\
\text { Medicina }\end{array}$ & Resolução CFM no 1.643/2002 & $\begin{array}{l}\text { Define e disciplina a prestação de } \\
\text { serviços através da telemedicina. }\end{array}$ \\
\hline $\begin{array}{l}\text { Conselho Federal de } \\
\text { Medicina }\end{array}$ & Resolução CFM no 1.958/2010 & $\begin{array}{l}\text { Define e regulamenta o ato da consulta } \\
\text { médica. }\end{array}$ \\
\hline $\begin{array}{l}\text { Conselho Federal de } \\
\text { Medicina }\end{array}$ & $\begin{array}{l}\text { Processo-Consulta CFM no } \\
50 / 2016 \text { (Parecer CFM no } \\
14 / 2017)\end{array}$ & $\begin{array}{l}\text { Uso de novos métodos e recursos } \\
\text { tecnológicos para comunicação entre } \\
\text { médicos e pacientes. }\end{array}$ \\
\hline $\begin{array}{l}\text { Conselho Federal de } \\
\text { Medicina }\end{array}$ & $\begin{array}{l}\text { Resolução CFM no 2.227/2018 } \\
\text { Define e disciplina a telemedicina como } \\
\text { forma de prestação de serviços médicos } \\
\text { mediados por tecnologias. }\end{array}$ \\
\hline $\begin{array}{l}\text { Conselho Federal de } \\
\text { Medicina }\end{array}$ & Resolução CFM no 2.228/2019 & $\begin{array}{l}\text { Revoga a Resolução CFM no 2.227/2018 } \\
\text { e restabelece expressamente a vigência } \\
\text { da Resolução CFM no 1.643/2002 }\end{array}$ \\
\hline
\end{tabular}




\begin{tabular}{|l|l|l|}
\hline $\begin{array}{l}\text { Conselho Regional de } \\
\text { Medicina do Estado do } \\
\text { Ceará }\end{array}$ & Resolução no 56/2020 & $\begin{array}{l}\text { Dispõe sobre o atendimento médico por } \\
\text { telemedicina. }\end{array}$ \\
\hline $\begin{array}{l}\text { Conselho Regional de } \\
\text { Medicina da Bahia }\end{array}$ & Resolução no 363/2020 & $\begin{array}{l}\text { Dispõe sobre a assistência médica a } \\
\text { partir de ferramentas de telemedicina. }\end{array}$ \\
\hline $\begin{array}{l}\text { Conselho Regional de } \\
\text { Medicina do Distrito } \\
\text { Federal }\end{array}$ & Resolução no 453/2020 & $\begin{array}{l}\text { Dispõe sobre a assistência médica a } \\
\text { partir de ferramentas de telemedicina e } \\
\text { telessaúde. }\end{array}$ \\
\hline $\begin{array}{l}\text { Conselho Regional de } \\
\text { Medicina do Rio de } \\
\text { Janeiro }\end{array}$ & Resolução no 305/2020 & $\begin{array}{l}\text { Dispõe sobre o atendimento médico por } \\
\text { telemedicina. }\end{array}$ \\
\hline $\begin{array}{l}\text { Conselho Regional de } \\
\text { Medicina do Paraná }\end{array}$ & Resolução no 217/2020 & $\begin{array}{l}\text { Dispõe sobre o atendimento médico por } \\
\text { telemedicina. }\end{array}$ \\
\hline $\begin{array}{l}\text { Conselho Regional de } \\
\text { Medicina do Mato } \\
\text { Grosso }\end{array}$ & Resolução no 02/2020 & $\begin{array}{l}\text { Dispõe sobre a assistência médica a } \\
\text { partir de ferramentas de telemedicina e } \\
\text { telessaúde. }\end{array}$ \\
\hline Ministério da Saúde & Portaria do MS no 467/2020 & $\begin{array}{l}\text { Dispõe, em caráter excepcional e } \\
\text { temporário, sobre as açóes de } \\
\text { telemedicina. }\end{array}$ \\
\hline $\begin{array}{l}\text { Congresso Nacional } \\
\text { Dispõe sobre o uso da telemedicina } \\
\text { durante a crise causada pelo coronavírus }\end{array}$ \\
\hline Fone: no 13.989/2020
\end{tabular}

Fonte: elaboração própria.

Feito o levantamento, desenvolveu-se uma análise contextual e histórica da legislação, de modo a evitar ou minimizar interpretações dogmáticas, desenvolvendo os pesquisadores uma "reflexão crítica externa sobre os documentos" (6), cotejando-os com a revisão da literatura jurídica especializada sobre telemedicina. Buscou-se, por fim, contextualizar a telemedicina brasileira e abordar o exercício da medicina por meio da teleconsulta, a partir das suas peculiaridades instituídas pela Lei n-13.989, de 15 de abril de 2020 (3), enfatizando o direito de informação do paciente e os riscos de negligência informacional médica, consoante conceituação apontada por Calado (7).

\section{A consulta médica e o exame físico do paciente}

A Resolução CFM n 1.958/2010, a qual "Define e regulamenta o ato da consulta médica, a possibilidade de sua complementação e reconhece que deve ser do médico assistente a identificação das hipóteses tipificadas nesta resolução" (8), estabelece a definição de consulta médica em seu artigo primeiro: 
Art. 1ํ Definir que a consulta médica compreende a anamnese, o exame físico e a elaboração de hipóteses ou conclusões diagnósticas, solicitação de exames complementares, quando necessários, e prescrição terapêutica como ato médico completo e que pode ser concluído ou não em um único momento.

Analisando o texto normativo podemos evidenciar que nele estão contidos na definição de consulta os seguintes atos médicos: a anamnese, o exame físico do paciente e o diagnóstico (hipóteses ou conclusões), além de solicitação de exames complementares e prescrição. Nem todos os atos contidos na definição são necessariamente praticados pelo médico em todos os casos, posto que nem sempre, por exemplo, será necessário um exame complementar ou uma determinada prescrição. Contudo, o exame físico direto do paciente parece, em primeiro plano, fazer parte essencial da consulta médica.

O Código de Ética Médica (CEM) (9), no art. 37, proíbe a prescrição médica sem exame direto do paciente, ressalvando os casos de urgência/emergência nos quais não seja possível o exame, mas ainda assim determinando a sua realização tão logo cesse a impossibilidade.

Art. 37. Prescrever tratamento e outros procedimentos sem exame direto do paciente, salvo em casos de urgência ou emergência e impossibilidade comprovada de realizálo, devendo, nesse caso, fazê-lo imediatamente depois de cessado o impedimento, assim como consultar, diagnosticar ou prescrever por qualquer meio de comunicação de massa.

$\S 1^{\circ} \mathrm{O}$ atendimento médico a distância, nos moldes da telemedicina ou de outro método, dar-se-á sob regulamentação do Conselho Federal de Medicina.

$\S 2^{\circ}$ Ao utilizar mídias sociais e instrumentos correlatos, o médico deve respeitar as normas elaboradas pelo Conselho Federal de Medicina.

A conjugação dessas duas normativas leva-nos à seguinte ilação: as consultas com prescrição, em regra, exigem o exame direto do paciente; não deveriam, portanto, ser realizadas à distância. A consulta sem prescrição e sem exame direto do paciente permanece controversa. Há apenas o estabelecimento pelo Código de Ética de que não se faça consulta por meio de comunicação de massa. Para alguns, o exame físico direto do paciente é imprescindível e indissociável do ato médico complexo que é a consulta médica, para outros não, como fica evidente nas divergências regulatórias dos Conselhos Regionais como adiante será apontado.

Catapan e Calvo (10) em revisão de literatura bastante densa afirmam que "a incapacidade de realização do exame físico apresenta-se como principal desvantagem da teleconsulta por vídeo", noticiando a existência de estudos na Austrália e no Japão que indicam que essa não deve ser uma barreira (com destaque para as especificidades de cada 
estudo). As autoras advogam que deve prevalecer a adoção de postura mais cautelosa na medida em que "há falta de evidências que justifiquem a adoção da teleconsulta para pacientes novos", realçando que "[...] restam dúvidas quanto à exclusão dessa premissa para cobertura assistencial em áreas geograficamente remotas [...]" (10).

Seguindo o caminho oposto, e defendendo abertamente a regulamentação da teleconsulta em solo brasileiro, Schmitz et al (11) analisam o tratamento dado a matéria nos Estados Unidos, Europa e em outros países. Ao tratarem da teleconsulta nos 50 estados norte-americanos, os autores fazem um diagnóstico amplo da legislação, referindo que "pela legislação aprovada até dezembro de 2015" tem-se o seguinte cenário:

Dezenove estados a permitem sem restrições; • Dos demais 31, apenas 3 exigem uma consulta presencial inicial, um exige paridade 1:1 e os outros ao menos um atendimento presencial em algum momento; - Somente três estados exigem a presença de outro profissional de saúde (médico ou não) junto ao paciente no momento da interação virtual (11).

Isto é, a teleconsulta é uma realidade nos Estados Unidos da América, sendo certo que a imensa maioria dos estados dispensa o exame físico prévio do paciente (consulta presencial).

A teleconsulta é também uma realidade para vários países europeus, onde "[...] 24 dos 28 países membros possuem legislação sobre teleconsulta”, dos quais apenas a Alemanha, Eslováquia e Itália a proíbem, enquanto Áustria, Escócia, Grécia e Polônia estudam o tema. Em todos os demais países a teleconsulta é, então, permitida, com mais ou menos restrições (11). Os autores concluem seu estudo afirmando que existe uma real necessidade de regulamentação da teleconsulta no Brasil, ao reconhecer que ela já é uma realidade, ainda que informal:

\begin{abstract}
A regulamentação da teleconsulta no Brasil também é uma necessidade para os médicos. Tirar esse procedimento da informalidade permitirá a justa valorização financeira pelo tempo dispendido aos pacientes fora da consulta presencial e possibilitará vários arranjos de otimização de tempo e de custos, com vantagens para médicos e pacientes, como hoje já é possível para psicólogos e seus pacientes. (11)
\end{abstract}

Talvez já tenha chegado o momento da "nova ética digital na prática médica" referida por Lopes et al (12), ao referir que a Resolução CFM 2.227/2018 (13) - revogada em 2019 - teria inaugurado esse novo momento. O fundamento para essa nova ética seria justamente o fato de que "[...] a Resolução da telemedicina confronta o Código de Ética Médica em alguns dos seus dispositivos, sobretudo em relação à desnecessidade de exame direto do 
paciente antes da prescrição, como estabelecido no art. 37 do Código de Ética." (12). Contudo, não se pode olvidar que, cotidianamente, os médicos e médicas brasileiras realizam consultas por telefone e até mesmo por WhatsApp. Essa prática médica é tão frequente que a Sociedade Brasileira de Citopatologia, em 2016, formalizou consulta ao CFM sobre o tema.

No Processo-Consulta CFM n 50/2016 (14), o conselheiro relator descreveu a consulta da seguinte forma: "Tendo em vista inúmeras consultas em relação ao uso do aplicativo WhatsApp, o CFM elaborou este parecer." Quer dizer, o Conselho Federal reconheceu o uso do aplicativo WhatsApp e ofertou o parecer para regular a questão. Dentre os vários fundamentos suscitados pelo conselheiro relator, merecem destaque os seguintes:

Está claro que o médico pode receber mensagens no WhatsApp e responder, como sempre o fez, atendendo telefonemas de pais aflitos com seu pequeno filho cuja febre não baixava e precisava ouvir seu pediatra com as orientações seguras e tranquilizadoras.

[...] podemos assegurar que a troca de informações entre pacientes e médicos, quando se tratar de pessoas já recebendo assistência, é permitida para elucidar dúvidas, tratar de aspectos evolutivos e passar orientações ou intervenções de caráter emergencial. Se relevante, deve orientar o paciente a comparecer ao consultório e registrar em prontuário ou ficha clínica, no primeiro momento em que o médico tiver acesso ao mesmo. (14)

Entendemos que a ratio decidendi do parecer CFM no 14/2017 do CFM (15) é vinculante e possibilita a comunicação entre o médico e o seu paciente por WhatsApp, restringindo, contudo, a pacientes que já sejam atendidos pelo médico.

Steavrns e Abravmowicz (16), ao tratar dos precedentes, constroem uma definição de ratio decidendi como as proposições que realmente foram decididas, baseadas em fatos do caso e condutoras do julgamento, o que nos parece ocorrer no Processo-Consulta julgado pelo CFM que resultou no parecer acima. Frise-se que o parecer possui eficácia vertical no sistema conselhal, pois vincula os Conselhos Regionais e, por conseguinte, os profissionais nele inscritos, conforme definido expressamente na Nota Técnica CFM no 162/2013 (17):

Como o Conselho Federal de Medicina é a instância máxima na definição da conduta médica em todo o território nacional, sendo suas decisões normativas de observância cogente por todos os médicos do Brasil, asseverando-se tal constatação em face das competências que Ihe foram atribuídas pelo o art. $7^{\circ}$ da Lei $n .{ }^{\circ} 12.842 / 2013$, a aprovação pelo CFM de pareceres sobre matéria médica, inclusive no que se refere àquilo que possa ser considerado experimental, passa a ser de observância obrigatória por todos os Conselhos Regionais de Medicina, bem como por todos os médicos que legalmente exerçam a medicina em território nacional. 
O parecer CFM № 14/2017 (15) estaria a permitir que pacientes já atendidos pelo médico possam consultá-lo por telefone ou WhatsApp. Noutras palavras, reconhece como ético o fato notório e usual de "consultas de monitoramento" de pacientes e de seus familiares pelo WhatsApp e por telefone. A conclusão do parecer (15) está vazada nos seguintes termos:

\begin{abstract}
O WhatsApp e plataformas similares podem ser usados para comunicação entre médicos e seus pacientes, bem como entre médicos e médicos em caráter privativo para enviar dados ou tirar dúvidas com colegas, bem como em grupos fechados de especialistas ou do corpo clínico de uma instituição ou cátedra, com a ressalva de que todas as informações passadas tem absoluto caráter confidencial e não podem extrapolar os limites do próprio grupo, nem tampouco podem circular em grupos recreativos, mesmo que composto apenas por médicos, ressaltando a vedação explícita em substituir as consultas presenciais e aquelas para complementação diagnóstica ou evolutiva a critério do médico por quaisquer das plataformas existentes ou que venham a existir.
\end{abstract}

Assentadas essas premissas no tocante à consulta médica e às práticas médicas corriqueiras por meio de tecnologias da informação, passa-se a analisar a legislação vigente sobre a teleconsulta.

\title{
A lei da telemedicina excepcional brasileira e a teleconsulta nela permitida
}

O CFM possui resolução regulando a telemedicina, qual seja, a Resolução CFM no 1.643/2002 (3) que "Define e disciplina a prestação de serviços através da Telemedicina". Ocorre que essa resolução apenas tangencia o tema. Diz que a telemedicina objetiva a assistência, a educação e a pesquisa. Nem a indica, nem a proíbe. Deixa para o médico a "liberdade e completa independência para decidir se utiliza ou não recomenda o uso da Telemedicina para seu paciente", recomendando que tal decisão funde-se no critério central do benefício do paciente.

No ano de 2018 o CFM aprovou, por meio da Resolução CFM no 2.227/2018, o uso mais amplo da telemedicina, revogando a tímida Resolução CFM no 1.643, de 2002 (3). Contudo, após curto período de tempo, a resolução foi revogada (Resolução CFM nº 2.228/2019) por uma forte rejeição das demais entidades médicas: Associação Médica Brasileira, sindicatos e até mesmo Conselhos Regionais de Medicina. Frise-se que, na exposição de motivos da Resolução CFM no 2.228/2019 (18), consta que o pedido de revogação da Resolução CFM no 2.227/2018 (13) foi motivado pelas manifestações dos médicos e das suas entidades representativas: 


\begin{abstract}
Em virtude do alto número de propostas encaminhadas pelos médicos brasileiros para alteração dos termos da Resolução CFM № 2.227/2018 - a qual define critérios para a prática da telemedicina no País-, que já chegam a 1.444 contribuições, até o momento; em atenção, ademais, ao clamor de inúmeras entidades médicas, que pedem mais tempo para analisar o documento e enviar também suas sugestões de alteração; e, por fim, tendo em vista a necessidade de tempo para concluir as etapas de acolhida, compilação, estudo, organização, apresentação e deliberação de todo o material já recebido e do que ainda será recebido, possibilitando uma análise criteriosa de cada uma dessas contribuições, com o objetivo de entregar aos médicos e à sociedade em geral um instrumento que seja eficaz em sua função de normatizar a atuação do médico e a oferta de serviços médicos a distância mediados pela tecnologia, sendo sensível às manifestações dos médicos brasileiros e das entidades representativas da classe, solicito revogar a Resolução CFM № 2.227/2018.
\end{abstract}

Na resolução revogada a teleconsulta fora assim definida: "Art. $4^{\circ} \mathrm{A}$ teleconsulta é a consulta médica remota, mediada por tecnologias, com médico e paciente localizados em diferentes espaços geográficos" (13). Dessa definição, a lógica nos diria ser dispensável a

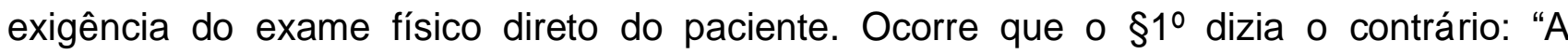
teleconsulta subentende como premissa obrigatória o prévio estabelecimento de uma relação presencial entre médico e paciente" (13).

O Conselho Federal de Medicina (CFM) regulou a matéria em 2002, tentou ampliar em 2018 e voltou atrás em 2019. Ocorre que, em 2020, veio a pandemia decorrente do novo coronavírus e o Ministério da Saúde deu um passo à frente, tendo o Congresso Nacional agido rápido e regulado de modo excepcional e temporariamente a matéria.

A acepção do vocábulo telemedicina e o que nele estaria contido ainda é objeto de divergência entre os estudiosos, pelo que é preciso estabelecer, antes de qualquer coisa, a sua delimitação conceitual contemporânea, suas espécies e os demais conceitos correlatos, de modo a evitar confusão terminológica e imprecisões técnicas.

Segundo a Declaração de Tel Aviv (19) a telemedicina é definida como "o exercício da medicina à distância, cujas intervenções, diagnósticos, decisões de tratamentos e recomendações estão baseadas em dados, documentos e outra informação transmitida através de sistemas de telecomunicação", sendo certo que existem várias espécies, listando e explicando (em caráter não exaustivo) os seguintes tipos (segundo o item 5 da declaração): a teleassistência (5.1) que corresponde a "uma interação entre o médico e o paciente geograficamente isolado ou que se encontre em um meio e que não tem acesso a um médico local"; a televigilância (5.2), que seria "uma interação entre o médico e o paciente, onde se transmite informação médica eletronicamente (pressão arterial, eletrocardiogramas, etc.) ao médico, o que permite vigiar regularmente o estado do paciente"; a teleconsulta (5.3) como 
sendo "uma interação onde o paciente consulta diretamente o médico, utilizando qualquer forma de telecomunicação, incluindo a internet" e a teleinterconsulta (5.4) como "uma interação entre dois médicos: um fisicamente presente com o paciente e outro reconhecido por ser muito competente naquele problema médico". Essa declaração foi revogada em 2006 pela Associação Médica Mundial (WMA, sigla de World Medical Association), que adotou em 2007 a Declaração sobre a Ética da Telemedicina (20) na sua 58ª Assembleia Geral em Copenhague - e modificada em 2018 -, trazendo definições mais sucintas para a telemedicina:

A telemedicina é a prática da medicina à distância, na qual intervenções, diagnósticos, decisões terapêuticas e recomendações subsequentes de tratamento são baseadas em dados do paciente, documentos e outras informações transmitidas pelos sistemas de telecomunicações. A telemedicina pode ocorrer entre um médico e um paciente ou entre dois ou mais médicos, incluindo outros profissionais de saúde. $(20)^{3}$

\section{Entre os autores brasileiros, pode-se citar Maldonado, Marques e Cruz (21) para}

quem a

[t]elemedicina, em sentido amplo, pode ser definida como o uso das tecnologias de informação e comunicação na saúde, viabilizando a oferta de serviços ligados aos cuidados com a saúde (ampliação da atenção e da cobertura), especialmente nos casos em que a distância é um fator crítico.

Uma definição ampla e atual da telemedicina contida em estudo internacional sobre o tema é fornecida por Gogia:

Telemedicina, telessaúde, saúde a distância e medicina a distância são expressões que se referem ao uso de tecnologias da informação e comunicação (TICs) para fornecer serviços de saúde onde existe separação física entre os prestadores de cuidados e / ou os destinatários, tanto em distâncias longas quanto curtas. Trata-se de transmitir voz, dados, imagens e informações, em vez de mover destinatários, profissionais de saúde ou educadores. Abrange aspectos preventivos e curativos dos serviços de saúde para os destinatários. As interações podem ser entre destinatários, prestadores ou educadores e, ultimamente, dispositivos computadorizados autônomos, além de trabalharem em dispositivos móveis. A telemedicina descreve serviços clínicos remotos na forma de contato com o paciente e o clínico. Inclui diagnóstico, monitoramento, conselhos, lembretes, educação, intervenção e admissões remotas. ${ }^{4}(22)$

\footnotetext{
${ }^{3}$ Tradução livre de: "Telemedicine is the practice of medicine over a distance, in which interventions, diagnoses, therapeutic decisions, and subsequent treatment recommendations are based on patient data, documents and other information transmitted through telecommunication systems. Telemedicine can take place between a physician and a patient or between two or more physicians including other healthcare professionals."

4 Tradução livre de: "Tele distance medicine or health is the use of information and communication technologies (ICTs) to deliver health services where there is physical separation between care providers and/or the recipients over both long and short distances. It is about transmitting voice, data, images, and information rather than moving care recipients, health professionals, or educators. It encompasses preventive as well as curative aspects of healthcare services for recipients. The interactions can be between care recipient(s), care providers or educators, and lately also computerized devices-
} 
Não se pode confundir a telemedicina com outras terminologias já em uso corrente, como o é caso da saúde digital (eSaúde), que tem mais de 51 definições diferentes, dentre as quais se inclui "o uso de tecnologias da informação e comunicação (TIC) no apoio à saúde e áreas relacionadas à saúde, incluindo serviços de saúde, vigilância e educação em saúde, conhecimento e pesquisa" ${ }^{5}$ (22). Isto é, ao se falar de saúde digital estar-se-á falando do provimento do suporte tecnológico, do conjunto de medidas de apoio, mas não do exercício da medicina em si (ato privativo de profissional médico).

Segundo Gogia (22) "o reconhecimento formal do termo telemedicina começou na década de 1920, quando sinais bidirecionais de televisão e áudio foram usados para se comunicar"6, sendo desenvolvida e aplicada essa tecnologia nas décadas seguintes, com destaque para a possibilidade de transmissão de radiografia por meio de circuitos telefônicos entre cidades (anos 1940), transmissão de vídeo e dados médicos complexos (final da década de 1950 e no início da década de 1960). Foi nessa época que ocorreu a primeira consulta de telemedicina em vídeo em tempo real (1959), quando "a Universidade de Nebraska usou a televisão interativa (IATV) para transmitir exames neurológicos” (22), referindo, por fim, à telepsiquiatria que teria surgido na sequência. Como se vê, a telemedicina é amplamente utilizada, possuindo a Malásia, por exemplo, uma lei sobre a telemedicina desde o ano de 1997 ( Telemedicine Act) (23). Enquanto no cenário mundial já se aborda a telemedicina 2.0 (22), o CFM reluta em admitir a teleconsulta como espécie de telemedicina no Brasil. De acordo com seu entendimento atual, são espécies de telemedicina em caráter excepcional apenas a "teleorientação: para que profissionais da medicina realizem à distância a orientação e o encaminhamento de pacientes em isolamento;" o "telemonitoramento: ato realizado sob orientação e supervisão médica para monitoramento ou vigência à distância de parâmetros de saúde e/ou doença" e a "teleinterconsulta: exclusivamente para troca de informações e opiniões entre médicos, para auxílio diagnóstico ou terapêutico." (4).

\footnotetext{
standalone, as well as working through a mobile. Telemedicine describes remote clinical services in the form of patient and clinician contact. It includes diagnosis, monitoring, advice, reminders, education, intervention, and remote admissions."

5 Tradução livre de: "The use of information and communication technologies (ICT) in support of health and health-related field, including health care services, health surveillance and health education, knowledge and research."

${ }^{6}$ Tradução livre de "Formal recognition of the term telemedicine started in the 1920s when two-way television and audio signals were used to communicate. [...] the University of Nebraska used interactive television (IATV) to transmit neurological examinations [...]"
} 
Apesar desse entendimento do CFM, a Lei no 13.989, em vigor, esclarece em sua ementa que "Dispõe sobre o uso da telemedicina durante a crise causada pelo coronavírus (SARS-CoV-2)" (5), ou seja, a lei autoriza, de modo expresso e excepcional, o uso de tecnologias da informação para o exercício da medicina em virtude do estado de calamidade pública decorrente do coronavírus. Essa autorização está expressa em seu art. 10: "Esta Lei autoriza o uso da telemedicina enquanto durar a crise ocasionada pelo coronavírus (SARSCoV-2)", deixando claro que o seu caráter é excepcional e transitório em seu art. 20: "Durante a crise ocasionada pelo coronavírus (SARS-CoV-2), fica autorizado, em caráter emergencial, o uso da telemedicina" (5). A definição da telemedicina está vazada nos seguintes termos: "o exercício da medicina mediado por tecnologias para fins de assistência, pesquisa, prevenção de doenças e lesões e promoção de saúde". Contudo, essa definição não é rígida,

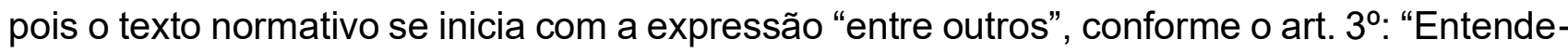
se por telemedicina, entre outros, o exercício da medicina mediado por tecnologias para fins de assistência, pesquisa, prevenção de doenças e lesões e promoção de saúde" (5). Após permitir e definir a telemedicina, a lei exige do médico uma série de cautelas em virtude da impossibilidade de realização de exame físico durante a consulta. Nesse sentido, a lei traz um reforço do dever de informar do médico, que vai se somar a todas as regras deontológicas existentes no CEM, determinando que "o médico deverá informar ao paciente todas as limitações inerentes ao uso da telemedicina, tendo em vista a impossibilidade de realização de exame físico durante a consulta" (Art. $4^{\circ}$ ) (5). Quer dizer, o médico tem a obrigação de explicar ao paciente a eventual importância ou relevância do exame físico para o diagnóstico no caso concreto. É justamente nesse aspecto que surgem os riscos de negligência informacional que serão abordados no próximo tópico. Assim, o art. 4ำ trata especificamente da teleconsulta, ainda que use o termo telemedicina no início do artigo, tanto que refere expressamente à consulta em seu texto na parte final. Cotejando a definição de telemedicina trazida no art. $3^{\circ}$ da lei, que é amplo e aberto, podemos sim concluir que o art. 4ำ trata da teleconsulta (como espécie de telemedicina), ainda que assim não o faça de modo expresso, trazendo um reforço do dever de informação do médico, decorrente de regras deontológicas e legais. A norma trata ainda do padrão a ser seguido pelos médicos no atendimento telepresencial e do reconhecimento do direito à remuneração, logo, não existem dúvidas quanto à possibilidade de exercício da atividade na saúde privada nem na saúde pública pela expressa menção ao serviço prestado no SUS. Quanto ao serviço 
prestado, a norma estabelece que a telemedicina deverá seguir "os padrões normativos e éticos usuais do atendimento presencial" (5), isto é, aplica-se o CEM e demais resoluções pertinentes. Assim está grafado o art. 5ํ da lei:

Art. 5ㅇ A prestação de serviço de telemedicina seguirá os padrões normativos e éticos usuais do atendimento presencial, inclusive em relação à contraprestação financeira pelo serviço prestado, não cabendo ao poder público custear ou pagar por tais atividades quando não for exclusivamente serviço prestado ao Sistema Único de Saúde (SUS) (5).

Existem outras questões de relevo na norma, mas, por conta do recorte do presente trabalho, não se adentrará nos vetos, tanto do art. 6ํㅡㄴ, no qual havia a previsão de que "[c]ompetirá ao Conselho Federal de Medicina a regulamentação da telemedicina após o período consignado no art. $2^{\circ}$ desta Lei”, bem como do parágrafo único do art. $2^{\circ}$ que disciplinava a questão da prescrição/receita, cuja solução adequada fora encontrada pelo Conselho Federal de Medicina (CFM), em conjunto com o Instituto Nacional de Tecnologia da Informação (ITI) e o Conselho Federal de Farmácia (CFF), que disponibilizaram por meio do endereço eletrônico ${ }^{7}$ uma ferramenta para a emissão de atestados ou receitas médicas em meio eletrônico, dentro do escopo delineado na Portaria do Ministério da Saúde no 467/2020 (4).

Assim, passa-se a discorrer sobre os direitos informacionais do paciente e correlatos deveres dos médicos e dos riscos deles decorrentes.

\section{Os riscos de negligência médica informacional na teleconsulta}

O médico tem a obrigação de informar ao paciente a eventual importância ou relevância do exame físico para o caso concreto. O CFM, por meio da Resolução CFM № 2.217/2018 (9), editou o CEM vigente, do qual são sujeitos passivos os médicos, abrangendo a atividade médica considerada em si mesma, além das atividades de ensino, pesquisa e extensão. O CEM trata ainda de inúmeras situações que implicam, direta e indiretamente, pacientes e instituições públicas e privadas, inclusive operadoras de planos de saúde. Sua aplicação já foi, inclusive, objeto de análise pelo Superior Tribunal de Justiça (STJ), onde a ministra relatora Nancy Andrighi (REsp 1180815/MG, DJe 26/08/2010) (24), em seu voto condutor, se referiu expressamente ao CEM, excluindo a responsabilidade civil de médico

\footnotetext{
${ }^{7}$ Disponível em https://prescricaoeletronica.cfm.org.br/
} 
que produziu prova de ter cumprido o dever de informar. Entre seus mandamentos principiológicos encontra-se o respeito à escolha do paciente:

\section{Capítulo I - PRINCÍPIOS FUNDAMENTAIS \\ $\mathrm{XXI}$ - No processo de tomada de decisões profissionais, de acordo com seus ditames de consciência e as previsões legais, o médico aceitará as escolhas de seus pacientes relativas aos procedimentos diagnósticos e terapêuticos por eles expressos, desde que adequadas ao caso e cientificamente reconhecidas. (9)}

Assim, o CEM, ao prescrever que "o médico aceitará as escolhas de seus pacientes" (9), trouxe uma nítida preocupação com a autonomia do paciente, contextualizando o exercício da sua vontade com recebimento de informações adequadas. O reconhecimento do direito do paciente a sua autonomia no contexto deontológico tem um significado contextual de relevo, posto que no passado a relação médico paciente era vista como vertical, onde o médico decidia por ser detentor do conhecimento, como se o paciente fosse um incapaz diante do acometimento da doença.

Destaque-se que a Portaria MS nำ 467, de 20 de março de 2020, estabelece que os médicos devem "atender aos preceitos éticos de beneficência, não-maleficência, sigilo das informações e autonomia" (art. $3^{\circ}$, Parágrafo único, I) ao utilizarem-se das "ações de telemedicina" (4). Mesmo antes da vigência do novo CEM, já havia certo consenso na doutrina de que em qualquer atividade médica dever-se-ia realizar o dever de informar, documentando-se (25), solicitando ao paciente que assinasse um termo de consentimento para a realização do ato, onde constem todas as informações prestadas, o assim chamado termo de consentimento informado ou termo de consentimento livre e esclarecido.

Em seu art. 22, o CEM veda ao médico "deixar de obter consentimento do paciente ou de seu representante legal após esclarecê-lo sobre o procedimento a ser realizado, salvo em caso de risco iminente de morte" (9). Esse artigo revela, em verdade, uma proibição que contém duas imposições implícitas - o dever de esclarecimento do procedimento a ser realizado e o dever de obter o consentimento - e consagra o princípio da autonomia da vontade esculpido no princípio $\mathrm{n} \times$ XXI. Apenas o consumidor esclarecido poderá tomar uma decisão ou fazer uma escolha conscientemente, sob pena inclusive de considerar sua vontade viciada. Ao cumprir o dever de obter o consentimento, já deve ter cumprido o dever de informar, sendo esse pressuposto lógico para aquele, ao que referem Eduardo Dantas e Marcos Coltri: 
O primeiro artigo referente aos Direitos Humanos deixa explícito e evidente dois pilares deste Código de Ética Médica: direito à informação e autonomia do paciente. $\mathrm{Na}$ realidade, se analisando mais detidamente, a informação é pressuposto da autonomia. (26)

Já no art. 24, o CEM veda ao médico "deixar de garantir ao paciente o exercício do direito de decidir livremente sobre sua pessoa ou seu bem estar, bem como exercer sua autoridade para limitá-lo" (9), demonstrando claramente que deseja e queira romper com a visão de mundo pretérita, quando o médico estava posicionado hierarquicamente acima do paciente. Contudo, ao estarmos formalmente diante de uma relação contratual - contrato de prestação de serviço médico -, na prática, há certa sujeição do paciente ao médico, notadamente quando o paciente se encontra desacordado em cirurgia. Ainda assim, nem por isso tem o médico direito de agir sem o consentimento do paciente, a não ser que haja risco de morte, tendo o paciente de realizar suas escolhas, consoante a orientação do médico dada a limitação técnica do mesmo (26).

Esse poder decisório do paciente - autonomia da vontade - veda ainda ao médico intervir nas decisões do paciente ou de seu representante legal, ressalvando-se apenas no risco de morte, consoante o art. 31 do CEM: "Desrespeitar o direito do paciente ou de seu representante legal de decidir livremente sobre a execução de práticas diagnósticas ou terapêuticas, salvo em caso de iminente risco de morte" (9).

Eduardo Dantas e Marcos Coltri, ao comentarem esse artigo do CEM, referem o princípio da beneficência, já que impossibilitado o paciente, ou seus parentes, de manifestar sua vontade, "poderá o médico intervir para adotar as práticas diagnósticas, terapêuticas ou cirúrgicas que entenda necessárias, em benefício da preservação da vida." (26).

$\mathrm{O}$ art. 34 veda ao médico "[d]eixar de informar ao paciente o diagnóstico, o prognóstico, os riscos e os objetivos do tratamento, salvo quando a comunicação direta possa the provocar dano, devendo, nesse caso, fazer a comunicação a seu representante legal (9)". A informação tratada nesse artigo é qualificada, pois trata da situação atual do paciente (diagnóstico), tendo o paciente o direito de saber qual a doença que o acomete, bem como tem o direito de saber qual é o seu provável futuro (prognóstico), revestindo-se no dever do médico de prestar esclarecimento com base no estado atual da ciência médica, nas estatísticas e, consequentemente, nas chances que possui o paciente de reverter a situação atual. 
A regra deontológica também determina que o paciente tenha conhecimento do tratamento proposto, indo além da mera escolha pelo médico dos tratamentos possíveis e viáveis, para que o paciente possa sopesar os benefícios e malefícios (riscos) de cada um dos tratamentos possíveis, para só então, tomar uma decisão e realizar uma escolha. Nesse momento, após essa escolha esclarecida, é que deve o médico colher o consentimento do paciente, cujo estudo será realizado na sequência.

Percebe-se que o CEM consagrou o direito fundamental do paciente à informação, trazendo princípios e regras que devem ser observadas pelos médicos nas relações com paciente e familiares, objetivando assim a preservação de sua autonomia. Para maior aprofundamento sobre autonomia do paciente, remete-se o leitor para texto específico sobre o assunto (7).

Além de prestar as informações, também é preciso que o médico se certifique que o paciente está devidamente esclarecido, daí o surgimento do termo de consentimento livre $e$ esclarecido. Essa terminologia aparece na legislação pátria, na Resolução nำ 196, de 10 de outubro de 1996, do Conselho Nacional De Saúde (CNS) (27), ao tratar da pesquisa com seres humanos, incorporando em seu preâmbulo "os quatro referenciais básicos da bioética: autonomia, não maleficência, beneficência e justiça, entre outros, e visa assegurar os direitos e deveres que dizem respeito à comunidade científica, aos sujeitos da pesquisa e ao Estado.”. Em seu item II.11, apresenta a seguinte definição para o consentimento livre e esclarecido:

II.11 - Consentimento livre e esclarecido - anuência do sujeito da pesquisa e/ou de seu representante legal, livre de vícios (simulação, fraude ou erro), dependência, subordinação ou intimidação, após explicação completa e pormenorizada sobre a natureza da pesquisa, seus objetivos, métodos, benefícios previstos, potenciais riscos e o incômodo que esta possa acarretar, formulada em um termo de consentimento, autorizando sua participação voluntária na pesquisa. (27)

Contudo, a utilização deste termo não se restringe à pesquisa, sendo comumente chamado de consentimento informado, consentimento esclarecido, consentimento pósinformado, entre outros. O termo surgiu nos Estados Unidos, por meio de precedente judicial em caso patrocinado pelo advogado Paul G. Gebhard (28), a quem se atribui a paternidade do termo, no famoso caso Salgo v. Leland Stanford Jr. University, no ano de 1957. Para a doutrina americana do consentimento informado (29), existem dois deveres legais impostos 
aos médicos: o dever de informar aos pacientes sobre o tratamento e obter deles o consentimento, tendo a grande maioria das cortes americanas a adotado como lei.

O professor José Roberto Goldim esclarece que:

[...] a normatização do uso do consentimento informado no Brasil se inicia na década de 1980. Dois documentos, um do Ministério da Saúde e outro do Conselho Federal de Medicina estabeleceram as bases para o uso, respectivamente, em pesquisa e assistência. (30)

As normas referidas são a Resolução nํ⒈081, de 12 de março de 1982, do Conselho Federal de Medicina, publicada na DOU em 23/03/1982 (31), e a Portaria n. 16, de 27 de novembro de 1981, do Ministério da Saúde, publicada no DOU 14/12/1981. (32)

O termo de consentimento informado (TCl) reflete um processo comunicacional entre o médico e o paciente, em que o primeiro presta informações e o segundo, compreendendoas, externa sua vontade em realizar o procedimento médico proposto. Segundo a doutrina médica, em artigo recente, encontramos a seguinte definição:

Consentimento informado é o registro em prontuário de uma decisão voluntária, por parte do paciente ou de seus responsáveis legais, tomada após um processo informativo e esclarecedor, para autorizar um tratamento ou procedimento médico específico, consciente de seus riscos, benefícios e possíveis consequências. (33)

Já para João Vaz Rodrigues (34), o dever de respeitar o paciente possui tríplice escopo: o de informar, confirmar e, por fim, obter o consentimento, restando claro que o consentimento informado é um processo complexo e não tão simples quanto se pensa ordinariamente, e, consequentemente, sujeito a falhas.

Na mesma esteira de raciocínio labora Gabriela Guz (35), para quem o consentimento é verdadeiro processo e não uma mera obtenção de um ciente ou de acordo, aduzindo ainda que "o processo contínuo de decisão pode acarretar diversas formas de 'consentimentos livres e esclarecidos' e 'recusas livres e esclarecidas', de tal sorte que, em verdade, trata-se, de uma decisão livre e esclarecida“. Até mesmo o uso da palavra termo, por si só, já caracterizaria um equívoco, vez que não traria a carga dinâmica necessária ao processo, que envolve a tomada de decisão. Afinal, o paciente recebe informações do médico, processa-as, pode recusá-las e, posteriormente, vir a tirar outras dúvidas, ouvir familiares para, por fim, concordar com esse ou aquele tratamento. Um simples e único termo não supriria nem materializaria um processo dinâmico, tanto que, para Gabriela Guz,

[o] consentimento livre e esclarecido corresponde, essencialmente, a um novo modelo de tomada de decisão no contexto da saúde individual que, ao fundamentar- 
se no respeito à autodeterminação do paciente, traz profundas alterações à própria dinâmica da relação médico-paciente, tradicionalmente pautada no poder de decisão do médico. (35)

O uso do instrumento escrito não dispensa o diálogo com o paciente, o que, de fato, ocorre mais frequentemente (36), e sendo discursivo o processo que visa a atender a tríplice finalidade do dever (informar, confirmar e obter o consentimento) seria este impossível de ser realizado por simples entrega de documento escrito, como observa André Pereira (37):

\begin{abstract}
O consentimento passou a ser visto por parte de alguns médicos como um mero requisito, um dos documentos para ter um 'dossier' clínico bem organizado e rapidamente as administrações hospitalares começaram a redigir formulários nos quais impõem cláusulas que visam proteger a instituição em caso de conflitos judiciários. Mais ainda é prática comum que esses formulários sejam entregues por funcionários administrativos, absolutamente desligados do acto médico, não tendo o paciente a possibilidade de obter informações adequadas sobre o seu conteúdo.
\end{abstract}

Outra não foi a conclusão da análise desenvolvida por Miguel Kfouri Neto (38), vez que há clara dificuldade no uso de formulários, notadamente porque, sendo o formulário genérico, não há a adequação e clareza que se espera para cada caso, afirmando o autor: "tanto a informação quanto o consentimento devem ser escritos, individualizados e testemunhados. A adoção de formulários é difícil, dadas as peculiaridades de cada caso."

A realidade brasileira não discrepa nesse particular da realidade portuguesa abordada por André Pereira, mas entre o almejado como conduta ideal e a realidade cotidiana há um grande hiato, porque no trato médico, em regra, estão presentes apenas o médico e o paciente, daí porque, segundo Consuelo Salamacha, é fundamental o TCl:

No que tange à relação entre médico e paciente, sendo ela estritamente confidencial, não há testemunhas nem documentos para comprovar uma possível advertência do profissional sobre os riscos de uma intervenção cirúrgica por ele aconselhada. Daí, uma vez mais, assevere-se a fundamental importância do termo de consentimento informado. (39)

Aguiar Júnior também concorda com a utilização do documento escrito como ideal para fins de prova no processo judicial, sendo mais cauteloso e admitindo a prova indireta realizada ao longo da instrução processual, notadamente porque, em regra, a realidade cotidiana demonstra que as informações são prestadas pelo médico, mas normalmente não são documentadas e muito menos reduzidas a termo e subscrita pelo paciente. Na opinião do ex-ministro:

[a] conclusão sobre o âmbito da informação e da existência do consentimento deve ser extraída, pelo juiz, do conjunto dos fatos provados, e mais precavido será o médico que obtiver declaração escrita do paciente ou de seu representante. (40) 
Esse processo comunicacional não pode nem deve ser apreciado apenas sob a ótica do direito, pois sua compreensão pelos pacientes vai além da análise jurídica da situação fática.

Nos Estados Unidos, onde o consentimento informado é obrigatório na maioria dos estados, Charles Lidz (29) realizou estudo e concluiu que a compreensão do paciente é geralmente incompleta e, ocasionalmente, ocorrem mal-entendidos. Os entendimentos dos pacientes não só eram muitas vezes idiossincráticos (condição única, relacionada a cada paciente), mas também tecnicamente limitados, pois o processo de compreensão não é instantâneo. A doutrina americana é repensada, quando alguns autores (41) afirmam que o consentimento informado não tem condições de ser totalmente específico e completo, bem como um consentimento específico não é eticamente melhor. Eis o impasse: o documento genérico não atende aos critérios de adequação e clareza da nossa legislação e o específico demais não é eticamente indicado, podendo até mesmo causar um dano ao paciente.

Nessa linha de pensamento o CFM editou a Recomendação CFM nำ1/2016 que "[d]ispõe sobre o processo de obtenção de consentimento livre e esclarecido na assistência médica", na qual se estabelece, no art. 1ํ, que "nas decisões sobre assistência à saúde dos pacientes, os médicos devem levar em consideração o documento Consentimento Livre e Esclarecido" (42).

Assim, a emissão de vontade do paciente deve ser considerada após todo o processo comunicacional, como resultado da escolha do paciente orientada pelos esclarecimentos adequados do médico, sem que existam omissões ou exageros por parte do médico, vez que a "falha na informação ou na comunicação é considerada defeito no produto ou serviço, ensejando a responsabilização civil, se produzir dano." (43).

Em se tratando de relação de consumo, o Superior Tribunal de Justiça (STJ), no REsp no 1540580/DF (DJe 04/09/2018), entendeu que há

"[...] uma prestação de serviços especial [n]a relação existente entre médico e paciente, cujo objeto engloba deveres anexos, de suma relevância, para além da intervenção técnica dirigida ao tratamento da enfermidade, entre os quais está o dever de informação" (44).

$E$, justamente em decorrência dessa relação diferenciada entre médico e paciente, um dos deveres anexos é o dever de informação, caracterizando-se como

"[...] a obrigação que possui o médico de esclarecer o paciente sobre os riscos do tratamento, suas vantagens e desvantagens, as possíveis técnicas a serem 
empregadas, bem como a revelação quanto aos prognósticos e aos quadros clínico e cirúrgico, salvo quando tal informação possa afetá-lo psicologicamente, ocasião em que a comunicação será feita a seu representante legal" (44)

A decisão do STJ reconhece o dano extrapatrimonial causado pelo inadimplemento do dever de informação do médico com aplicação do CDC (45). Isto é, há risco claro de negligência informacional médica quando o profissional realizar 0 ato médico por teleconsulta e deixar de informar ao paciente questões de relevo.

Dentre os princípios e orientações da Declaração sobre a Ética na Telemedicina da Associação Médica Mundial (2007[2018]) (19), há disposição expressa sobre o consentimento informado adequado para a telemedicina. Ou seja, o termo de consentimento informado digital (TCl Digital) tem mais exigências que o consentimento tradicional, na medida em que é preciso que o médico explicite o funcionamento da telemedicina, dando ênfase nas questões da privacidade e da possibilidade de falhas tecnológicas e eventuais violações de confidencialidade, dentre outras questões peculiares a caso concreto.

A advertência de Lopes et al (12) é no sentido de que:

[...] a regulamentação apropriada da extraordinária telemedicina deixe de ser uma promessa, convertendo-se em instrumento de equidade e justiça social, sob pena de, em vez de uma janela para o futuro, a telemedicina converter-se em uma porta para o caos.

Assim, a questão da teleconsulta está longe de ter um entendimento pacífico, como apontam Lopes et al (12), ao tratarem da Resolução CFM nำ2.227/2018 (13):

\footnotetext{
Operadoras de planos de saúde, grandes hospitais e empresas de soluções para telemedicina estão eufóricos. Na outra ponta, os médicos alegam que a medicina sofreu um duro golpe desferido por quem tinha o dever de precatar pelo seu exercício ético, transformando os médicos em verdadeiros operadores de telemarketing.
}

Então, surgem algumas questões: como deve ser feita a formalização da obtenção do consentimento do paciente para evitar a caracterização da negligência informacional médica? Quais são todas as limitações inerentes ao uso da telemedicina? Essas limitações variam de acordo com a especialidade? Se o paciente já tiver uma relação anterior com o médico como aferir a existência ou não de relevância decorrente da impossibilidade de realização de exame físico durante a consulta virtual? A complexidade das respostas possíveis justifica o aprofundamento do tema e revela inexoravelmente os riscos que estão sendo assumidos pelos médicos e médicas de todo o Brasil que, dentre de sua autonomia, resolvem realizar a teleconsulta. 
Catapan e Calvo (10) assinalam que:

Embora existam muitas preocupações sobre a adoção da teleconsulta médica, o cenário mundial demonstra investimentos e crescente representatividade nas pesquisas sobre sua utilização e apropriação para o aprimoramento do cuidado, assim como a análise de suas limitações e seus benefícios.

Destacam ainda as autoras que "[...] alguns médicos ressaltam a importância em resistir à pressão até que sejam produzidas evidências consistentes de que a teleconsulta pode poupar recursos e ser benéfica." (10), mas enquanto alguns resistem, os fatos acontecem se sobrepondo a desejos e aspirações, e a realidade muda.

É de se observar que a Agência Nacional de Saúde Suplementar (ANS), por meio da Nota Técnica no 6/2020/GGRAS/DIRAD-DIPRO/DIPRO (46), tratou da "[c]obertura assistencial dos atendimentos realizados por meios remotos, empregando-se tecnologias que viabilizem o atendimento não presencial (telessaúde)", externando o seguinte entendimento:

Por todo o exposto, considerando que os atendimentos realizados por meio de comunicação à distância não se caracterizam como novos procedimentos, mas apenas como uma modalidade de atendimento não presencial, esta área técnica entende que não se faz necessário nem adequado atualizar o Rol de Procedimentos e Eventos de Saúde no que tange à inclusão de procedimentos (anexo I) e/ou alteração de diretrizes de utilização (Anexo II), nem tampouco às regras de cobertura dispostas na RN 428/2017, devendo-se considerar que os atendimentos por meio de telessaúde já são de cobertura obrigatória, na medida em que cumprem as orientações normativas dos Conselhos Profissionais de Saúde e/ou do Ministério da Saúde.

A nota ainda estabelece que as operadoras devem garantir condições adequadas para os atendimentos remotos, esclarecendo que os atendimentos presenciais só devem ocorrer em situações imprescindíveis, tendo em vista a necessidade de isolamento social. As operadoras, então, não tardaram em criar e divulgar amplamente a nova modalidade de atendimento (Figuras 1 a 4 ). 
Figura 1. Amil divulga seu serviço de telemedicina

\section{O cuidado certo no seu smartphone ou tablet}

Neste momento de tanta apreensão em relação à saúde, estamos disponibilizando a Telemedicina Amil para todos os nossos clientes. Com isso, você pode receber o cuidado certo sem se expor a riscos

desnecessários. Todos os clientes dos nossos planos médicos Amil. Amil One e Amil Fácil agora contam com essa novidade.

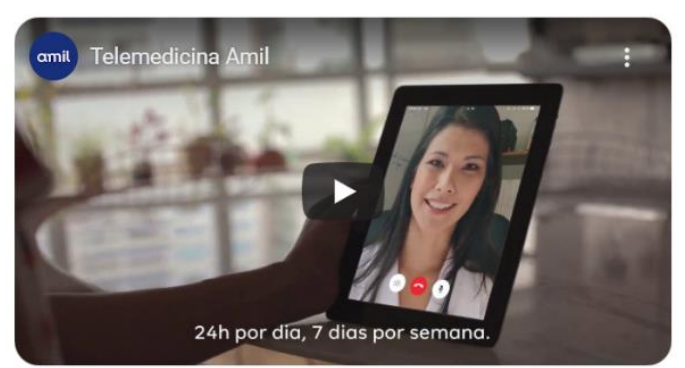

\section{Cliente Amil tem acesso à Telemedicina pelo número:}

\section{1 sers}

Fonte: Amil (47)

Figura 2. Bradesco Saúde divulga serviço de informações sobre o coronavírus pelo celular

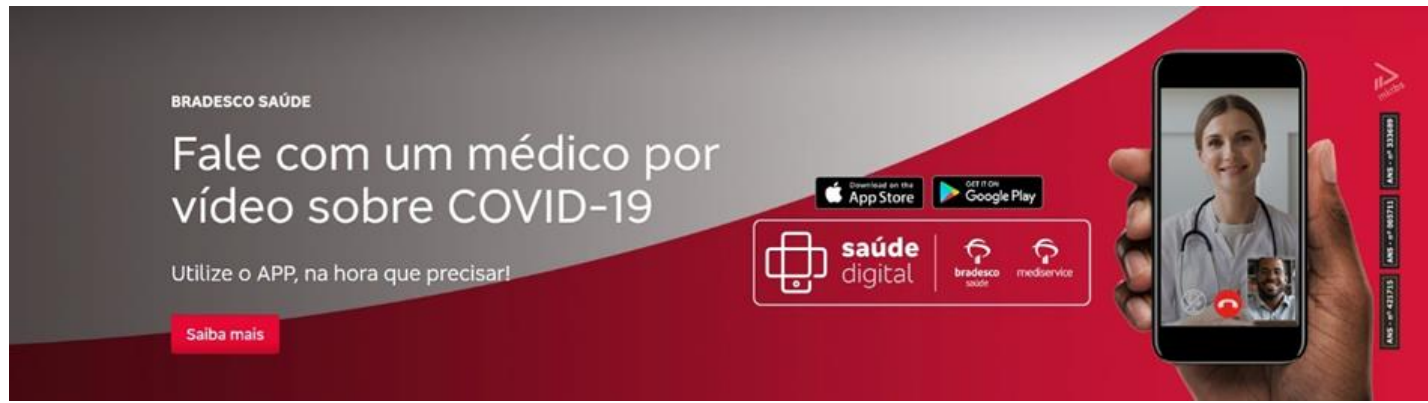

Fonte: Bradesco Saúde (48)

Figura 3. Sulamérica divulga seu serviço de teleconsulta

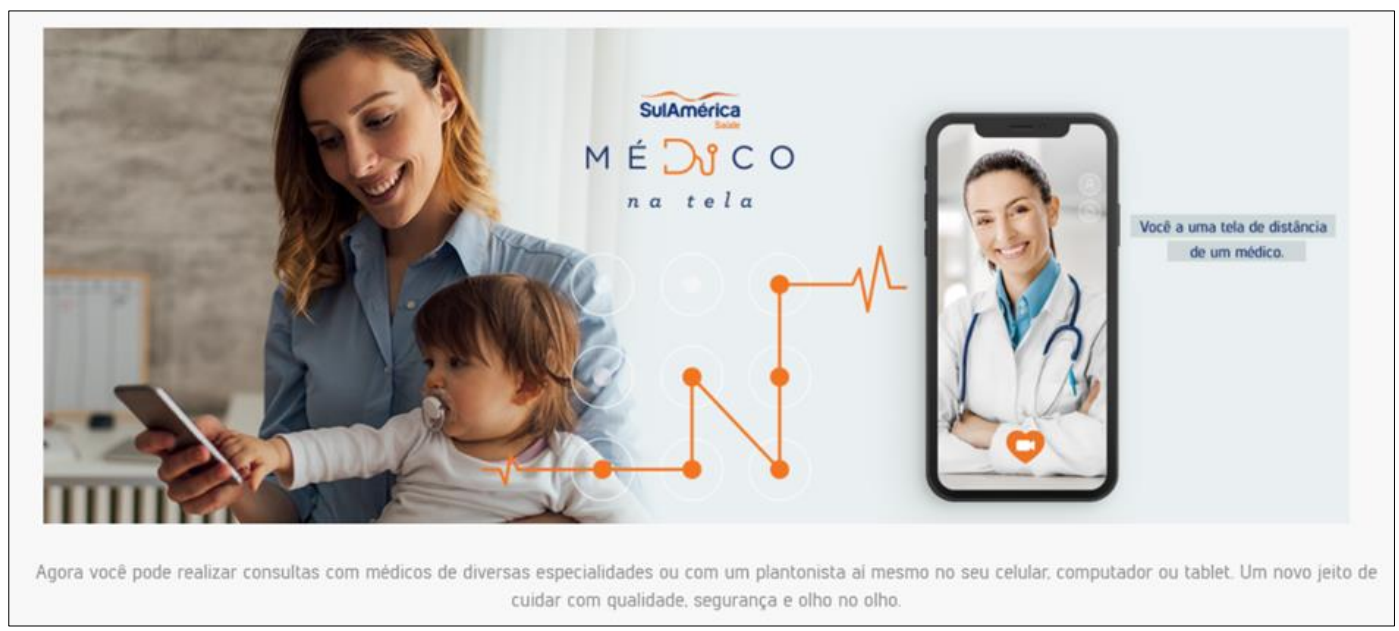

Fonte: Sulamérica (9) 
Figura. 4. A operadora Hapvida divulga a ampliação de seu serviço de teleconsulta

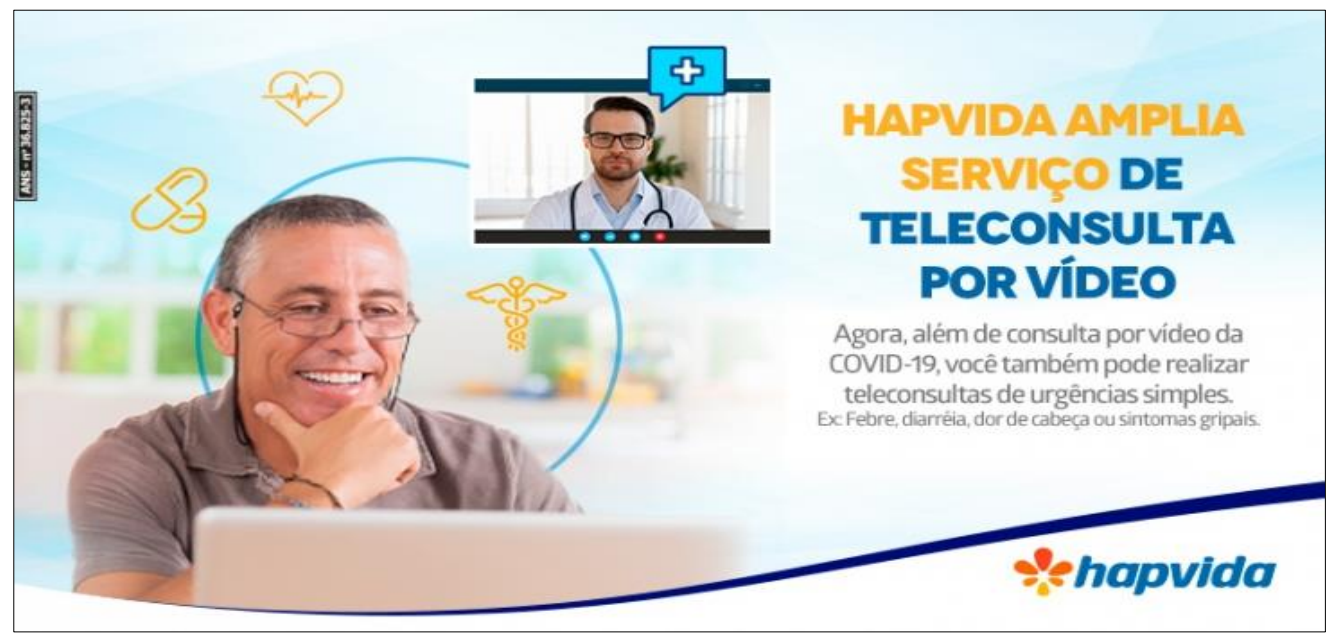

Fonte: Hapvida (50)

Com tudo isso, cresce o risco de falhas no processo comunicacional para os médicos e para os pacientes, que podem ser consideradas negligências informacionais médicas, notadamente porque não existe uma padronização dos mecanismos e dos procedimentos, muitos menos dos aplicativos e sistemas utilizados. Até mesmo os entendimentos dos Conselhos Regionais de Medicina dos Estados discrepam entre si. Cite-se o exemplo da Resolução no 56, de 1ํ de abril de 2020, do Conselho Regional de Medicina do Estado do Ceará (CREMEC) que "[d]ispõe sobre o atendimento médico por Telemedicina durante a pandemia de SARS-CoV2/COVID-19" (51). Nessa resolução, em seu art. 1o, está expressamente autorizada a consulta telepresencial, enquanto o art. $2^{\circ}$, além da teleorientação, do telemonitoramento e da teleinterconsulta, define a teleconsulta (alínea "d"):

Art. 1ำ Autorizar, em regime de excepcionalidade, a realização de consulta, orientação e acompanhamento médico no Estado do Ceará, utilizando a Telemedicina, através de qualquer meio de comunicação eletrônica, garantido o sigilo de ambas as partes.

Art. 2ำ A telemedicina, no contexto desta Resolução, é composta pelas seguintes modalidades de atendimento médico:

a) Teleorientação - avaliação remota do quadro clínico do paciente, para definição e direcionamento ao tipo adequado de assistência que necessita.

b) Telemonitoramento - ato realizado sob orientação e supervisão médica para monitoramento ou vigilância à distância de parâmetros de saúde e/ou doença;

c) Teleinterconsulta - troca de informações (clínicas, laboratoriais e de imagens) e opiniões entre médicos, para auxílio diagnóstico ou terapêutico; e

d) Teleconsulta - a troca de informações (clínicas, laboratoriais e de imagens) entre médico e paciente, com possibilidade de prescrição e atestado médico. 
Contudo, a resolução restringe a possibilidade de teleconsultas, uma vez que seu art. $6^{\circ}$ determina "a Telemedicina na modalidade de Teleconsulta somente está autorizada para pacientes que já são atendidos pelo médico, sendo vedada a realização da primeira consulta de forma não presencial." Ou seja, o primeiro atendimento só seria possível por meio de uma consulta presencial.

Já na Bahia, o Conselho Regional de Medicina editou a Resolução CREMEB noㅡ 363/2020, a qual "[d]ispõe sobre a assistência médica a partir de ferramentas de telemedicina, durante estado de calamidade pública que determina isolamento, quarentena e distanciamento social" (52). O texto normativo faculta aos médicos a assistência telepresencial (art. $1^{\circ}$ ), permitindo expressamente a prática da teleconsulta sem prévio exame do paciente, conforme art. $2, \S 4^{\circ}$, adiante transcrito:

Art. $1^{\circ} \mathrm{Fica}$ facultada aos profissionais médicos a assistência não presencial com uso de ferramentas de telemedicina e telessaúde nos termos dessa Resolução.

Art. $2^{\circ}$ São as modalidades de telemedicina e telessaúde a que se refere o Art. $1^{\circ}$ da presente Resolução:

$\S 1$ 을 Teleorientação, para que profissionais da medicina realizem à distância a orientação e o encaminhamento de pacientes em distanciamento social.

$\S 2^{2}$ TTelemonitoramento, ato realizado sob orientação e supervisão médica para monitoramento ou vigilância à distância de parâmetros de saúde e/ou doença.

$\S 3$ o Teleinterconsulta, exclusivamente para troca de informações e opiniões entre médicos, para auxílio diagnóstico ou terapêutico.

$\S 4^{\circ}$ Teleconsulta, consulta com a possibilidade de prescrição, por parte do médico, de tratamento, solicitação de exames ou outros procedimentos sem exame direto do paciente.

Enquanto isso, no Distrito Federal, seu Conselho Regional de Medicina editou a Resolução CRM-DF nำ453/2020 (53), a qual

"[d]ispõe sobre a assistência médica a partir de ferramentas de telemedicina e telessaúde, com base no Decreto Federal de Estado de Calamidade Pública, importando epidemias onde as orientações médicas incluem quarentena, isolamento e distanciamento social extenso".

A resolução se limita a reconhecer o contido no ofício CFM nำ1.756/2020 - COJUR do Conselho Federal de Medicina (2), nada tratando especificamente da teleconsulta.

O Conselho Regional do Rio de Janeiro também editou a resolução CREMERJ nº 305/2020 (54), a qual "[d]ispõe sobre o atendimento médico por Telemedicina durante a pandemia de SARS-CoV2/COVID-19", permitindo expressamente a teleconsulta (art. $1^{\circ}$ ), tratando-a como uma as modalidades da telemedicina (art. $2^{\circ}$, "d"). Contudo, a resolução do CREMERJ não permite a primeira consulta de forma telepresencial (art. 5ํㅜ) 
Art. 1ㅇ Autorizar a realização de consulta, orientação e acompanhamento médico no Estado do Rio de Janeiro, utilizando a Telemedicina, através de qualquer meio de comunicação digital ou telefônico, garantido o sigilo de ambas as partes.

Art. $2^{\circ}$, d) Teleconsulta - a troca de informações (clínicas, laboratoriais e de imagens) com possibilidade de prescrição e atestado médico.

Art. 5ำ A Telemedicina na modalidade Teleconsulta só está autorizada para pacientes que já são atendidos pelo médico, sendo vedada a realização da primeira consulta de forma não presencial.

Também no Paraná existe resolução dispondo sobre a telemedicina (CRM-PR no 217/2020) (55), a qual expressamente autoriza a realização de consulta telepresencial em seu art. $^{\circ} \stackrel{0}{ }$ da seguinte forma:

Art. 1ำ Autorizar a realização de consulta, orientação e acompanhamento médico no Estado do Paraná, utilizando a Telemedicina, pelo uso de qualquer meio de comunicação digital, garantido o sigilo de ambas as partes, tudo nos moldes da Portaria 467/20-MS.

No Mato Grosso, a Resolução CRM-MT nº 02/2020 (56) visa regular a telemedicina e chega a mencionar a consulta, mas não disciplina de modo expresso a teleconsulta, apresentando uma aparente contradição em seus próprios termos, pois enquanto o art. $2^{\circ}$ admite a consulta como uma das ações de telemedicina, a teleconsulta não aparece no texto como uma de suas modalidades, as quais se limitam a reproduzir o entendimento firmado pelo CFM, possuindo o mencionado art. $2^{\circ}$ dois "parágrafos únicos", fato esse gerador de certa confusão, posto que não está claro porque a consulta contida no caput não foi reconhecida como modalidade de telemedicina em seu parágrafo único:

\footnotetext{
Art. $2^{\circ}$ As ações de Telemedicina de interação à distância podem contemplar o atendimento pré clínico, de suporte assistencial, de consulta, monitoramento e diagnóstico, por meio de tecnologia da informação e comunicação, no âmbito do SUS, bem como na saúde suplementar e privada.

Parágrafo único. São reconhecidas as seguintes modalidades de telemedicina e telessaúde:

I - Teleorientação, para que profissionais da medicina realizem à distância a orientação e o encaminhamento de pacientes em distanciamento social extenso.

II - Telemonitoramento, ato realizado sob orientação e supervisão médica para monitoramento ou vigência à distância de parâmetros de saúde e/ou doença.

III - Teleinterconsulta, exclusivamente para troca de informações e opiniões entre médicos, para auxílio diagnóstico ou terapêutico.

Parágrafo único. $O$ atendimento de que trata o caput deverá ser efetuado diretamente entre médicos e pacientes, por meio de tecnologia da informação e comunicação que garanta a integridade, segurança e o sigilo das informações.
}

Diante de todas essas divergências, é forçoso reconhecer a necessidade de uma normatização nacional de modo a minimizar os riscos de negligência informacional médica, até mesmo porque a teleconsulta pode ocorrer entre pessoas (médicos e pacientes) 
localizadas em estados diversos da federação, não se podendo admitir tratamento diverso entre os entes federados, no particular.

\section{Considerações finais}

Este estudo visa contribuir para o aprimoramento da telemedicina no Brasil e, em especial, para a regulamentação da teleconsulta como modalidade de suma importância para a elevação da qualidade assistencial no país.

Inicialmente, abordou-se brevemente o contexto histórico da telemedicina, situando a teleconsulta nesse momento de pandemia decorrente do novo coronavírus. Evidenciou-se que a posição do atual CFM não está em consonância com a Associação Médica Mundial, nem com a prática comumente adotada nos Estados Unidos e na Europa, posto que a prática da teleconsulta não é expressamente reconhecida, o que gerou e gera uma situação problemática, em que os Conselhos Regionais de Medicina dos estados passaram a adotar posicionamentos divergentes quanto ao tema após a vigência da Portaria do Ministério da Saúde (MS) no 467, de 20 de março de 2020, e ainda em decorrência da Lei № 13.989, de 15 de abril de 2020 .

Assim, enquanto o Conselho Federal de Medicina (CFM) continua evitando regular a teleconsulta, numa visão restritiva da telemedicina, o Ministério da Saúde, por meio da Portaria n 467/2020, permitiu a sua utilização durante a pandemia, sobrevindo a Lei no 13.989, 15 de abril de 2020, que também a permite.

É certo que a Lei nำ13.989/2020 possibilita, enquanto durar a crise causada pelo coronavírus, o uso da telemedicina (e da teleconsulta), mas a norma deixa claro que o seu caráter é excepcional e transitório, de caráter emergencial. Ademais, após permitir e definir a telemedicina, a lei trata expressamente da teleconsulta, na medida em que exige do médico uma série de cautelas em virtude da impossibilidade de realização de exame físico durante a consulta à distância, deixando evidente o seu permissivo e a necessidade de sopesamento dos seus riscos para o paciente. Passada a pandemia serão suspensos os efeitos da lei, mas a sociedade já estará habituada a nova prática, sendo urgente a regulação da teleconsulta.

De um modo ou de outro, a teleconsulta veio para ficar, cabendo às autoridades regularem a matéria em definitivo para garantir a segurança jurídica necessária aos médicos e pacientes, potencializando e ampliando sua utilização no SUS, garantindo atendimento 
especializado a quem mais precisa, seguindo sempre o conselho da Associação Médica Mundial, isto é, a teleconsulta deve ser usada quando for a melhor opção disponível para o paciente.

Conclui o estudo que, enquanto não sobrevier norma regulando a matéria, mesmo após a pandemia, conforme a ratio decidendi do parecer CFM nํ14/2017 do CFM, pode-se afirmar que a teleconsulta é prática médica ética e possível, posto que não proibida pela Resolução CFM no 1.643, de 26 de agosto de 2002 (3), mas que depende de prévia relação médico-paciente, isto é, uma consulta presencial com exame físico anterior para as situações ordinárias, sendo diferida - e nunca dispensada - em situações de emergenciais, na linha da norma extraída do art. 37 do CEM. Também, é necessária a formalização de TCI digital na teleconsulta, que poderá ocorrer por qualquer meio de tecnologia da informação e comunicação desde que que garanta a integridade, segurança e o sigilo das informações. Tal instrumento é capaz de produzir a prova de que o médico cumpriu o seu dever de informar, esclarecendo o paciente acerca dos riscos inerentes à impossibilidade de exame direto, isentando-o da responsabilidade civil por negligência informacional.

\section{Referências}

1. Brasil. Câmara dos Deputados. Projeto de Lei no de 696 de 2020. Dispõe sobre o uso da telemedicina durante a crise causada pelo coronavírus (2019-nCoV). Brasília, 2020.

Disponível em:

https://www.camara.leg.br/proposicoesWeb/prop_mostrarintegra;jsessionid=0F93EF08779 E48A7FE7D2E3612D6B573.proposicoesWebExterno2?codteor $=1867127 \&$ filename $=$ Tramit acao-PL+696/2020

2. Brasil. Conselho Federal de Medicina. Ofício CFM nำ1.756/2020, de 19 de março de 2020. Resposta encaminhada ao Senhor Ministro de Estado da Saúde, Luiz Henrique Mandetta. Brasília, 2020 [Acesso em 02.abr.2020]. Disponível em: http://portal.cfm.org.br/images/PDF/2020_oficio_telemedicina.pdf.

3. Brasil. Conselho Federal de Medicina. Resolução CFM nำ1.643/2002, de 07 de agosto de 2002. Define e disciplina a prestação de serviços através da Telemedicina. Brasília, 2020 [Acesso em 02.abr.2020]. Disponível em:

https://sistemas.cfm.org.br/normas/visualizar/resolucoes/BR/2002/1643.

4. Brasil. Ministério da Saúde. Portaria MS nํ 467/2020, de 20 de março de 2020. Dispõe, em caráter excepcional e temporário, sobre as ações de Telemedicina, com o objetivo de regulamentar e operacionalizar as medidas de enfrentamento da emergência de saúde pública de importância internacional previstas no art. 3ํ da Lei nํ⒔979, de 6 de fevereiro de 2020, decorrente da epidemia de COVID-19. Brasília: DOU, 2020 [Acesso em 
20.mar.2020]. Disponível em: http://www.in.gov.br/en/web/dou/-/portaria-n-467-de20-demarco-de-2020-249312996.

5. Brasil. Presidência da República. Lei no 13.989/2020, de 15 de abril de 2020. Dispõe sobre o uso da telemedicina durante a crise causada pelo coronavírus (SARS-CoV-2). Brasília: DOU, 2020 [Acesso em 01.jun.2020]. Disponível em: http://www.planalto.gov.br/ccivil_03/_ato2019-2022/2020/Lei/L13989.htm.

6. Lamy, M. Metodologia da pesquisa: técnicas de investigação, argumentação e redação. São Paulo: Matrioska Editora; 2020.

7. Calado, VN. Responsabilidade civil do médico e consentimento informado: um estudo interdisciplinar dos julgados do STJ. Curitiba: Juruá; 2014.

8. Brasil. Conselho Federal de Medicina. Resolução CFM no 1.958/2010, de 10 de janeiro de 2011. Define e regulamenta o ato da consulta médica, a possibilidade de sua complementação e reconhece que deve ser do médico assistente a identificação das hipóteses tipificadas nesta resolução. Brasília, 10 de janeiro de 2011 [Acesso em 15.maio.2020]. Disponível em: https://sistemas.cfm.org.br/normas/visualizar/ resolucoes/BR/2010/1958.

9. Brasil. Conselho Federal de Medicina. Resolução CFM nํ⒉217/2018. Código de Ética Médica, de 01 de novembro de 2018. Aprova o Código de Ética Médica. Brasília, 2018 [Acesso em 15.maio.2020]. Disponível em:

https://sistemas.cfm.org.br/normas/visualizar/resolucoes/BR/2018/2217.

10. Catapan SC, Calvo MCM. Teleconsulta: uma Revisão Integrativa da Interação MédicoPaciente Mediada pela Tecnologia. Rev. bras. educ. med. 2020 [Acesso em 07.jul.2020]; 44 (1): e003. Disponível em: http://www.scielo.br/scielo.php?script=sci_arttext\&pid=S0100$55022020000100304 \& \operatorname{lng}=$ en\&nrm=iso.

11. Schmitz CAA, Gonçalves MR, Umpierre RN, Siqueira ACS, D'ávila OP, Bastos CGM et al. Teleconsulta: nova fronteira da interação entre médicos e pacientes. Rev. Bras. Med. Fam. Comunidade. 2017 Jjan-dez [Acesso em 15.maio.2020.]; 12(39):1-7. http://dx.doi.org/10.5712/rbmfc12(39)1540. Disponível em: https://rbmfc.org.br/rbmfc/article/view/1540.

12. Lopes MACQ, Oliveira GMM, Amaral Júnior A, Pereira ESB. Janela para o Futuro ou Porta para o Caos? In Arq Bras Cardiol. 2019; 112 (4): 461-465.

13. Brasil. Conselho Federal de Medicina. Resolução CFM no 2.227/2018, de 13 de dezembro de 2018. Define e disciplina a telemedicina como forma de prestação de serviços médicos mediados por tecnologias. Brasília, 2018 [Acesso em 02.abr.2020]. Disponível em: https://sistemas.cfm.org.br/normas/visualizar/resolucoes/BR/2018/2227.

14. Brasil. Conselho Federal de Medicina. PROCESSO-CONSULTA CFM $n^{\circ}$ 50/2016. Brasília, 2017 [Acesso em 02.abr.2020]. Disponível em: https://sistemas.cfm.org.br/normas/visualizar/pareceres/BR/2017/14 
15. Brasil. Conselho Federal de Medicina. Parecer CFM nำ14/2017 do Conselho Federal de Medicina (CFM). Brasília, 2017 [Acesso em 02.abr.2020]. Disponível em: https://sistemas.cfm.org.br/normas/visualizar/pareceres/BR/2017/14

16. Steavrns ML, Abravmowicz MB. Defining Dicta. Stanford Law Review. 2005 [Acesso em 09.mar.2019]; (56): 1-143. Disponível em: SSRN: https://ssrn.com/abstract=619124.

17. Brasil. Conselho Federal de Medicina. Nota Técnica № 162/2013, de 30 de outubro de 2013. Parecer. Processo Consulta. Obrigatoriedade. Ato normativo editado por outros conselhos regionais. Ato normativo do CFM. Obrigatoriedade de sua observância em todo o território nacional. Brasília, 2013 [Acesso em 15.maio.2020]. Disponível em: https://sistemas.cfm.org.br/normas/visualizar/notas/BR/2013/162.

18. CFM. Conselho Federal de Medicina. Resolução CFM nํ⒉228/2019, de 06 de fevereiro de 2019. Revoga a Resolução CFM n².227, publicada no D.O.U. de 6 de fevereiro de 2019, Seção I, p.58, a qual define e disciplina a telemedicina como forma de prestação de serviços médicos mediados por tecnologias, e restabelece expressamente a vigência da Resolução CFM no1.643/2002, publicada no D.O.U. de 26 de agosto de 2002, Seção I, p.205. Brasília, 2019 [Acesso em 02.abr.2020]. Disponível em: https://sistemas.cfm.org.br/normas/visualizar/resolucoes/BR/2019/2228.

19. Israel. World Medical Association. WMA Statement On Accountability, Responsibilities And Ethical Guidelines In The Practice Of Telemedicine. [Declaração de Tel Aviv, 1999]. Israel, 1999 [Acesso em 15.maio.2020]. Disponível em: https://www.wma.net/policiespost/wma-statement-on-accountability-responsibilities-and-ethical-guidelines-in-thepractice-of-telemedicine/.

20. Dinamarca. World Medical Association. WMA Statement On The Ethics Of Telemedicine. Copenhague, 2008 [Acesso em 15.maio.2020]. Disponível em: https://www.wma.net/policies-post/wma-statement-on-the-ethics-of-telemedicine/.

21. Maldonado JMSV, Marques $A B$, Cruz $A$. Telemedicina: desafios à sua difusão no Brasil. In Cad. Saúde Pública. 2016; 32 (Suppl 2): e00155615.

22. Gogia S, organizador. Fundamentals of telemedicine and telehealth. London: Elsevier/Academic Press; 2020.

23. Malaysia. Laws of Malaysia. Act 564. Telemedicine Act 1997. Disponível em: http://www.agc.gov.my/agcportal/uploads/files/Publications/LOM/EN/Act\%20564.pdf

24. Brasil. Superior Tribunal de Justiça. Recurso Especial 1180815/MG. Recorrente: Fernanda de Souza Panta. Recorrido: Carlos Fernando Hudson Nascimento. Relatora: Ministra Nancy Panta. Brasília, 19 de agosto de 2010 [Acesso em 08.jun.2020]. Disponível em: https://stj.jusbrasil.com.br/jurisprudencia/15932146/recurso-especial-resp-1180815-mg2010-0025531-0/inteiro-teor-16827834. 
25. Giostri HT. Responsabilidade médica - As obrigações de meio e de resultado: avaliação, uso e adequação. Curitiba: Juruá; 2004.

26. Dantas E, Coltri MV. Comentários ao Código de Ética Médica: Resolução CFM n. 1.931, de 17 de setembro de 2009. Rio de Janeiro: GZ Ed.; 2010.

27. Brasil. Conselho Nacional de Saúde. Resolução no 196, de 10 de outubro de 1996 do CNS. Aprovar as seguintes diretrizes e normas regulamentadoras de pesquisas envolvendo seres humanos. Brasília, 1996 [Acesso em 07.maio.2020]. Disponível em: http://bvsms.saude.gov.br/bvs/saudelegis/cns/1996/res0196_10_10_1996.html.

28. Gebhard PG. Developer of the Term 'Informed Consent'. New York Times. 1997 [Acesso em 07.maio.2020]. Disponível em: http://www.nytimes.com/1997/08/26/us/p-ggebhard-69-developer-of-the-term-informed-consent.html.

29. Lidz CW, Meisel A, Zerubavel E, Carter M, Sestak RM, Roth LH. Informed Consent: A Study of Decision Making in Psychiatry. New York, The Guilford Press; 1984.

30. Goldim, JR. Consentimento Informado no Brasil: Primeiras Normas. 1997 [Acesso em 19.dez.2009]. Disponível em http://www.ufrgs.br/bioetica/consbras.htm.

31. CFM. Conselho Federal de Medicina. Resolução 1.081, de 12 de março de 1982. Consentimento ou autorização dada pelo paciente ou responsável ao médico para necrópsia, provas necessárias ao diagnóstico e tratamento. Rio de Janeiro, 1982 [Acesso em 08.ago.2020]. Disponível em:

https://sistemas.cfm.org.br/normas/visualizar/resolucoes/BR/1982/1081.

32. Brasil. Ministério da Saúde. Portaria MS nำ16, de 27 de novembro de 1981. Termo de Conhecimento de Risco. Diário Oficial da União [da] República Federativa do Brasil (14/12/1981).

33. Hirschheimer MR, Constantino CF, Oselka GW. Consentimento informado no atendimento pediátrico. Revista Paulista de Pediatria. 2010 [Acesso em 06.ago.2010]; 28(2): 128-33. Disponível em http://www.scielo.br/pdf/rpp/v28n2/v28n2a01.pdf.

34. Rodrigues, JV. O consentimento informado para o acto médico no ordenamento jurídico português. Coimbra: Coimbra Editora; 2001.

35. Guz G. O consentimento livre e esclarecido na jurisprudência dos tribunais brasileiros. R. Dir. sanit. 2010 [Acesso em 21.abr.2011]; 11(1): 95-122. Disponível em http://www.revistasusp.sibi.usp.br/pdf/rdisan/v11n1/07.pdf.

36. Matielo FZ. Responsabilidade Civil do Médico. Porto Alegre: Sagra Luzzatto; 2001.

37. Pereira AGD. O consentimento informado na relação médico-paciente: estudo de Direito Civil. Coimbra Editora: Coimbra; 2004. 
38. Kfouri Neto M. Responsabilidade civil do médico. São Paulo: Editora Revista dos

Tribunais; 2001.

39. Salamacha, CTF. Erro médico: inversão do ônus da prova. Curitiba: Juruá; 2008.

40. Brasil. Superior Tribunal de Justiça (STJ). Diretoria de Informações Judiciais. Ministro Ruy Rosado de Aguiar Júnior: Homenagem. Brasília, 2005 [Acesso em 21.abr.2011]. p. 124. Disponível em http://bdjur.stj.gov.br/xmlui/bitstream/handle/2011/10223/45_Ministro_Ruy_Rosado_Aguiar. pdf? sequence $=6$.

41. Manson NC, O'neill O. Rethinking Informed Consent in Bioethics. Cambridge: Cambridge University Press; 2007 [Acesso em 07.maio.2011]. Disponível em http://books.google.com/books?id=kM3li88222kC\&printsec=frontcover\&hl=pt$\mathrm{BR} \# \mathrm{v}=$ onepage $\& \mathrm{q} \& \mathrm{f}=\mathrm{false}$.

42. CFM. Conselho Federal de Medicina. Recomendação CFM no 1/2016, de 06 de fevereiro de 2019. Define e disciplina a telemedicina como forma de prestação de serviços médicos mediados por tecnologias. [Revoga a Resolução CFM no 1643/2002]. [Acesso em 02.abr.2020]. Disponível em:

https://sistemas.cfm.org.br/normas/visualizar/recomendacoes/BR/2016/1

43. Densa R. Direito do Consumidor. São Paulo: Atlas; 2009.

44. Brasil. Superior Tribunal de Justiça. Recurso Especial 1540580 DF 2015/0155174-9. Recorrente: Dimas Pereira e Abrahão, Lindalva Goncalves Abrahão e Tiago Barboza Abrahão. Recorrido: Sociedade Beneficiente de Senhoras Hospital Sírio Libanês. Relatora: Ministro Lázaro Guimarães, 02 de agosto de 2018 [Acesso em 08.abr.2020]. Disponível em https://stj.jusbrasil.com.br/jurisprudencia/621592003/recurso-especial-resp-1540580-df2015-0155174-9/inteiro-teor-621592011.

45. Brasil. Presidência da República. Lei № 8.078, de 11 de setembro de 1990, Código de Defesa do Consumidor. Dispõe sobre a proteção do consumidor e dá outras providências. Brasília, 1990 [Acesso em 01.jun.2020]. Disponível em:

http://www.planalto.gov.br/ccivil_03/leis//8078compilado.htm.

46. Brasil. Agência Nacional de Saúde. Nota Técnica nำ 6/2020/GGRAS/DIRADDIPRO/DIPRO. 2020 [Acesso em 01 jun. 2020]. Disponível em: https://www.ans.gov.br/images/stories/noticias/pdf/covid_19/nota-tecnica-6-2020-diraddides-dides.pdf.

47. Amil Assistência Médica Internacional S/A. Telemedicina Amil. São Paulo, 2020 [Acesso em 22.jun. 2020]. Disponível em:

https://www.amilcuidadocerto.com.br/?utm_source=amil\&utm_medium=banner\&utm_camp aign=telemedicina.

48. Bradesco Seguros S/A. Informações Coronavírus Bradesco Saúde. Rio de Janeiro, 2020 [Acesso em 22.jun.2020]. Disponível em: 
https://www.bradescoseguros.com.br/clientes/produtos/plano-saude/informacoescoronavirus.

49. Sulamérica Saúde. Programa Saúde Ativa. Rio de Janeiro, 2020 [Acesso em 22.jun. 2020]. Disponível em: http://painel.programasaudeativa.com.br/medico-na-tela.

50. Hapvida Saúde. Rede de Teleconsulta. Fortaleza, 2020 [Acesso em 22.jun.2020]. Disponível em: http://www.hapvida.com.br/site/noticias/hapvida-amplia-rede-deteleconsulta.

51. Brasil. Conselho Regional de Medicina do Estado do Ceará - CREMEC. Resolução no 56 , de $1^{\circ}$ de abril de 2020. Dispõe sobre o atendimento médico por Telemedicina durante a pandemia de SARS-CoV2/COVID-19. Fortaleza, 2020 [Acesso em 15.maio.2020]. Disponível em: http://www.in.gov.br/en/web/dou/-/resolucao-n-56-de-1-de-abril-de-2020251068159.

52. Brasil. Conselho Regional de Medicina do Estado da Bahia - CREMEB. Resolução CREMEB n 363/2020. Dispõe sobre a assistência médica a partir de ferramentas de telemedicina, durante estado de calamidade pública que determina isolamento, quarentena e distanciamento social. Salvador, 2020 [Acesso em 15.maio.2020]. Disponível em: http://www.cremeb.org.br/index.php/normas/resolucao-cremeb-363-2020/.

53. Brasil. Conselho Regional de Medicina do Distrito Federal. Resolução CRM-DF no 453/2020. Dispõe sobre a assistência médica a partir de ferramentas de telemedicina e telessaúde com base no Decreto Federal de Estado de Calamidade Pública, importando epidemias onde as orientações médicas incluem quarentena, isolamento e distanciamento social extenso. Brasília, 2020 [Acesso em 15.maio.2020]. Disponível em: https://sistemas.cfm.org.br/normas/visualizar/resolucoes/DF/2020/453.

54. Brasil. Conselho Regional de Medicina do Estado do Rio de Janeiro. Resolução CREMERJ n $305 / 2020$. Dispõe sobre o atendimento médico por Telemedicina durante a pandemia de SARS-CoV2/COVID-19. Rio de Janeiro, 2020 [Acesso em 15.maio.2020]. Disponível em: https://sistemas.cfm.org.br/normas/visualizar/resolucoes/RJ/2020/305.

55. Brasil. Conselho Regional de Medicina do Estado do Paraná. Resolução CRM-PR no 217/2020. Dispõe sobre o atendimento médico por Telemedicina, as emissões de receitas e atestados médicos durante a pandemia da COVID-19 e a disponibilização do Serviço de Validação de Emissão de Atestado e Prescrição Médica por meio de opção no portal de serviços oferecido pelo CRM aos médicos do Estado do Paraná. Curitiba, 2020 [Acesso em 15.maio.2020]. Disponível em:

https://sistemas.cfm.org.br/normas/visualizar/resolucoes/PR/2020/217.

56. Brasil. Conselho Regional de Medicina do Mato Grosso. Resolução CRM-MT № 02/2020. Dispõe sobre a assistência médica a partir de ferramentas de telemedicina e telessaúde com base no Decreto Federal de Estado de Calamidade Pública, importando epidemias onde as orientações médicas incluem quarentena, isolamento e distanciamento social extenso. [Acesso em 15.maio.2020]. Disponível em: https://sistemas.cfm.org.br/normas/visualizar/resolucoes/MT/2020/2 


\section{Colaboradores}

Calado VN contribuiu com a concepção e redação final do artigo. Lamy $M$ contribuiu com a redação, revisão crítica e aprovação da versão final do artigo.

\section{Como citar este artigo:}

Calado VN, Lamy M. Teleconsulta médica: os limites éticos e o risco de negligência informacional. Cadernos lberoAmericanos de Direito Sanitário. 2020 jul./set.; 9(3): 89-122.

http://dx.doi.org/10.17566/ciads.v9i3.713 